\title{
Judgements during information seeking: a naturalistic approach to understanding the assessment of enough information
}

\author{
Jennifer M. Berryman ${ }^{1}$ \\ University of Technology, Sydney, Sydney, Australia
}

\begin{abstract}
In this article, theories of human judgement and decision making are reviewed and their use by library and information science researchers examined. A different perspective on judgement and decision making is offered by the field of naturalistic decision making (NDM) and the implications of this approach are considered for an expanded understanding of how judgements and decisions are made during information seeking. This discussion is illustrated by a case from a recent empirical investigation into how judgements of enough information are made in the workplace. The article concludes with a critical evaluation of the NDM approach. It is argued that NDM, a recent development in decision theory, offers a new perspective from which to investigate judgements and decisions during information seeking.
\end{abstract}

Keywords: Enough information; information seeking; judgement; decision making; naturalistic decision making; public policy.

\section{Introduction}

Rational decision making theories, both classical and behavioural, have been influential in the field of library and information science (LIS) research. These theories have developed and expanded our understanding of both how information is used in decision making [e.g. 1] and how people make judgements and decisions while seeking and using information [e.g. 2]. However the narrow definition of a decision that underpins theory development in the rational decision making tradition imposes limitations on the usefulness of the theories. It is

${ }^{1}$ Correspondence to: Jennifer Berryman, Information and Knowledge Management Program, Faculty of Humanities and Social Sciences, University of Technology, Sydney, PO Box 123, Broadway NSW 2007, Australia. E-mail: Jennifer.M.Berryman@student.uts.edu.au. 
Jennifer M. Berryman

timely to consider how more recent research in the field of human judgement and decision making may help LIS researchers understand judgements and decisions made during information seeking and use.

This paper summarises major themes in rational decision theory, drawing on examples from the LIS literature to illustrate their use in this field and discussing the constraints and limitations of relying solely on rational decision theory. The paper goes on to consider naturalistic decision making (NDM) - a relatively new approach to understanding decision making in real world settings. The principal tenets of NDM are described, characteristics of NDM are examined and their application to LIS research considered. A case description from recent doctoral research is used to illustrate NDM in practice; whereas an earlier paper [3] presented the research findings, this article explores the theoretical implications for the field of LIS. The author concludes that the emerging field of NDM can expand our understanding of how judgements and decisions are made when seeking information in dynamic and complex environments.

\section{Understanding decision making}

When seeking and using information, people must make choices [4], for example, about search strategies, or relevant resources. In making those choices, the information seeker draws on experience to help predict likely outcomes [4]; these predictions feed into an assessment or judgement about the comparative benefits of different courses of actions - that is, choosing between alternative options.

Choice between two or more options is the classical definition of a decision [5], a definition used, for example, in an investigation into young people's web searching behaviour in which the decision was operationalised as the choice of website to meet the information needs of the research participants [6]. However there is more to a decision than the moment of choice and a deeper understanding of decision making was captured by Jungermann, who saw decision making as a "multistage cognitive process" [7: 587] which may be broken down into three major phases. Firstly, the problem is identified or recognised, secondly, alternatives for action are considered (where judgement comes into play), and thirdly, an alternative to be pursued is selected (the decision) [8]. Our understanding of the second phase of this process was expanded by Hogarth [9]. Hogarth differentiated between two types of judgement: predictive and evaluative. Hogarth argued that predictive judgements are often used in sequential decision making and are of the type that can be proven wrong against a mathematical test. Contrasting with this type of judgement is evaluative judgement, judgement that reflects personal preferences, and possibly personal interaction with contextual factors. Evaluative judgements are not able to be weighed against an objective or external measure.

A decision, then, can be understood as that point at which an individual commits to action, a commitment which comes after an assessment of the options or choices available [1]. In summary, although the field of rational decision theory tightly defines what constitutes a decision, and research in this field focuses most attention on the moment of choice, decision making scholars understand the process of decision making to encapsulate much more than that single moment.

\section{Rational choice decision making dominant in LIS}

Under the broad umbrella of rational decision theory, two major strands of thought are evident: classical, or optimal, decision theory, and behavioural decision theory. The following section summarises major themes within these two strands, and considers how LIS researchers have drawn on these theories to inform understanding of judgements and decisions during information seeking.

Within the tradition of classical decision making, theorists have sought to define optimal decision making behaviour [10]. Examples of LIS research in this tradition have included use of Bayesian probability theory to investigate when and why people terminated a database search [e.g. 11]. This approach to understanding decision 


\section{Jennifer M. Berryman}

making presented difficulties when studying human decision making since "the consequences [of decisions] are not known with certainty” [12: 2] making assessments of likely outcomes impossible. Assumptions regarding rationality in human behaviour, including decision making, were challenged as empirical studies revealed that preferences guiding behaviour were far from clear [13] . Further, it became apparent that no matter how desirable this approach might be, it did not always reflect human behaviour [14, 15]. As a result, scholars of the behavioural school of decision making began to investigate the conditions under which deviations from the optimal models occurred [16].

The theories of bounded rationality and satisficing behaviour [17] have been a major contribution of the behavioural school of decision theory. Recognising that people face a range of limitations to optimal rationality, Simon originally conceptualised cognitive limitations, such as "limitations of knowledge and computational capacity” [17: 291] and time constraints [18]. Additional constraints have subsequently been posited, particularly in the workplace. Simon [19] suggested that organisational goals may constrain decision making, and Harrison [1] further suggested "legal restrictions, organisational structure and the locus of responsibility" may also constrain workers. With their optimal rationality bounded, people are willing to accept an option good enough to meet their needs - they choose not to pursue the optimal outcome, behaviour which Simon termed 'satisficing'. Satisficing acts as a "stop rule" [20: 3]. In an information context, satisficing suggests people are likely to stop searching once they have enough information for their purposes [12, 17].

Library and information science researchers have found the concept of satisficing useful in understanding human information seeking behaviour [21]. Early examples of the use of bounded rationality and associated stopping rules included the work of Kraft and Waller [22] who drew on Bayesian probability theory when hypothesising that levels of satiation or disgust would determine rules for an optimal stopping point in a database search. They noted the difficulty a user faces in predetermining their level of satiation or disgust and concluded a need existed for a dynamic model capable of "reflecting the changes in the user's information requirements" during the progress of the search. Morehead and Rouse [23] also conducted experimental research into the ways in which information seekers assessed different attributes when making relevance assessments. Morehead and Rouse tested several models and three stopping rules - time constraints, diminishing returns and frustration. They concluded "additional situational rules" were needed in the models to "accurately mimic individual search strategies” [23]. - 204

Another important contribution of behavioural decision theory was the recognition that, because of uncertainty, people use estimates of probability in developing heuristics that guide their decision making [15, 24]. Heuristics are "simple rules for making decisions with realistic mental resources" [25] and their use simplifies judgement and decision making by allowing people to recognise patterns and "apply rules of appropriate behaviour accordingly” [12: 11-15]. Heuristics are created and shaped by consideration of what worked before, by experience and by training [14]. Commonly used heuristics include the availability heuristic, where a prediction about a likely outcome is based on readily available recollections, and the adjustments heuristic, where a prediction is based on a familiar position used as an anchor [24].

Recent LIS studies [2, 26] have continued to investigate decision making during information seeking using bounded rationality as a conceptual framework. Agosto's [26] study focused on the third phase of Simon's phase model: the evaluation of possible solutions and the choosing of one. In her study, Agosto operationalised the decision as the choice of website to meet the information needs of young web surfers [6]. Agosto found study participants were constrained by limitations of time and cognitive capacity but concluded that satisficing alone did not adequately account for all the influences on participants' decisions to stop their searches. She reported additional stop rules, including physical discomfort and boredom, which caused participants to stop searching before they had found a website that was good enough to meet their information needs.

Zach [2] sought to find out which stop rules influenced arts administrators to end their information seeking. In similar fashion to Agosto, Zach operationalised the decision as deciding when the information need was met. Zach reported that participants satisficed when there was conflict between time factors and a sense of comfort with the amount of information found. Further, they were willing to stop even if more information was known to be available. Zach reported that participants followed a "highly intuitive process" which drew on "personal experience or expertise" [2: 32] and concluded that while this intuitive approach may be acceptable in "familiar 


\section{Jennifer M. Berryman}

situations", it would not serve arts administrators well when they faced tasks of increased complexity or high impact.

In summary, rational decision theory has served LIS researchers well. However, the mathematic modelling and the experimental contexts used in the development of rational decision theory [27] are very different from the real world settings in which people confront choices during the process of seeking and using information. The earlier studies such as those by Kraft and Waller [22] and Morehead and Rouse [23] typically excluded the possibility of participants receiving and acting on feedback during the decision making process, a constraint that necessarily limits the applicability of these theories to real world situations [28]. More recently, Agosto [26] and Zach [2] both concluded that satisficing as defined by Simon did not fully account for the stopping behaviour of participants in their studies. Rational decision theory, then, may not be sufficiently robust to explain what we know about human information behaviour and judgements and decisions made while seeking information.

\section{Decision making as a process}

The theories of rational decision making are limited in their capacity to explain fully how people handle all the "typical confusions and pressures", the "missing information, time constraints, vague goals and changing conditions" [29: 1] that rational decision theories acknowledged but removed from the research equation. Researchers in the field of naturalistic decision making (NDM) widened the lens of their research focus to find out how people make judgements and decisions in real world settings (for a full discussion of this emerging field of study, see Montgomery et al [30] and Zsambok and Klein [31]).

Focusing initially on skilled decision makers, NDM scholars studied the decision making behaviour of experts in emergency situations. Subsequently, interest in NDM expanded to other fields, including systems design [32] and organisational decision making [33]. Three principles underlie the models developed by NDM researchers: the "holistic evaluation" of options, recognition-based decision making, and satisficing in the form of taking the first feasible option [34: 2]. The NDM approach also explicitly recognises the criticality of contextual factors in shaping decision making. Early studies highlighted eight factors characteristic of the environments in which NDM research was carried out [30]:

- $\quad$ Ill-structured problems

- Uncertain and dynamic environments

- Shifting, ill-defined or competing goals

- Action, feedback loops

- $\quad$ Time stress

- High stakes

- Multiple players

- $\quad$ Organisational goals and norms.

Five of these factors are related to the "contextual considerations [that] constitute frames of reference" for human information seekers [35: 752]; these are the uncertain and dynamic environments, the time stress, high stakes, multiple players, and organisational goals and norms. Two factors are more closely related to the task in which information seeking is embedded, that is, the "activity to be performed in order to accomplish a goal" [36: 416]; these factors are the ill-structured nature of the problems confronting the individual, and shifting, ill-defined or competing goals.

A major finding of the early NDM research was that decision making was experienced as a process. In organisational settings, in particular, research findings have revealed that the rational model of "preference-driven choices from among alternatives" [37: 372] is not always characteristic of managerial decision making. Rather decisions are reached through a series of steps, "with feedback at each step" [33: 93] and judgements need to be made throughout the process. As a result, research attention has focused increasingly on the role of judgement in 
Jennifer M. Berryman

decision making [10]. These contextual and task-related factors and the iterative process of decision making are represented in Figure 1:

Figure 1: Decision making as a process

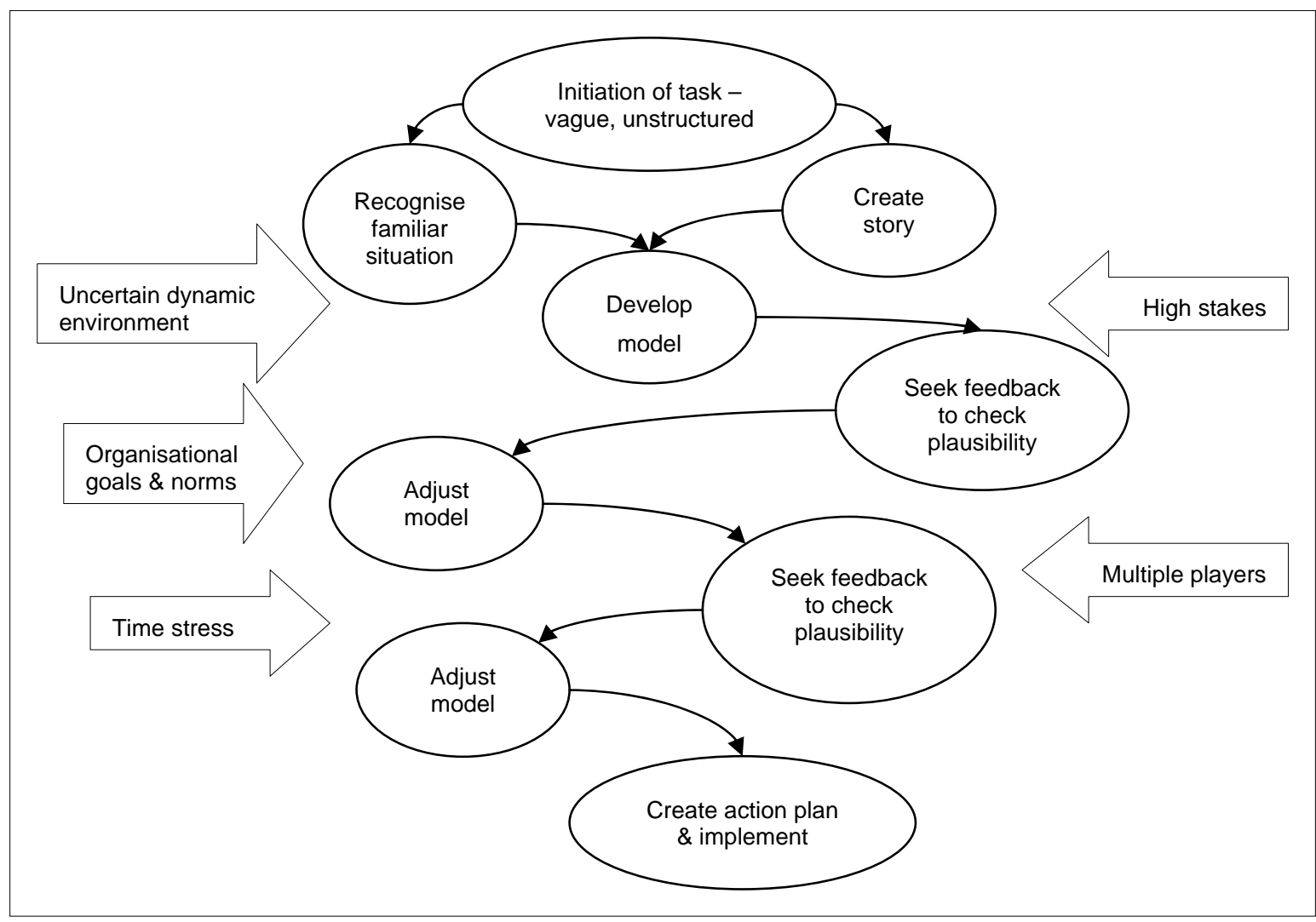

Adapted from Bryant [34] and Montgomery et al [30]

How do people make judgements and decisions in contexts characterised by complexity and uncertainty, and working with tasks that are vague and unstructured? If the situation is familiar, the decision maker constructs a mental model of the situation. If the situation is unfamiliar, the decision maker will seek more information before constructing this mental model. Decision theorists Lipshitz and Ben Saul [38: 293] define mental models as "specific situation representations, differentiating them from schemata which are more enduring "abstract cognitive structures” which help shape the mental model. The mental models of experienced decision makers are "formed over a period of time by various experiences of a similar nature" [39: 297]. The mental model, seen primarily as a cognitive representation of the problem, is changed, updated and refreshed by the decision makers as they move through time and space [38].

At the initial step in a task or problem, an individual begins to gather information about the task or problem, to build a "display" [38: 299]. The display is not all that can be known about the situation, but only what is available to the individual. The individual takes the information available and crafts it into the mental model which will guide initial actions in response to the situation [29]. Drawing from experience, mental models help people both predict outcomes and understand their environment. Importantly in the workplace, both display and the developing mental model are shaped by three factors: values held by staff, specific work goals and the planned work actions intended to achieve those goals [40].

Experienced decision makers continually assess the feasibility of this mental model through a process of mental simulation, a technique that in situations of uncertainty helps them continually check the plausibility of the 


\section{Jennifer M. Berryman}

model as the situation unfolds and changes around them [41]. Thus they continually assess and update their understanding of a situation as part of an iterative process towards determining appropriate action [42], identifying "critical factors in the environment" and developing an understanding of "what will happen in the near future" [43: 270]. From that assessment flows appropriate action that may be selected from an existing repertoire or tested via mental simulation. The mental modelling, updating and plausibility checking help experts see the flaws in their simulations. The experts do not evaluate and choose between a range of options but rather take action on the first feasible model that presents itself [41]. While this response has parallels with satisficing behaviour, the decision itself is not represented as the classical definition of a choice between two or more options.

\subsection{NDM in practice: Assessing enough information}

The following section draws on recent empirical research to illustrate how the contextual factors and the decision-making process described by NDM researchers are evident in work-based information seeking and use. The research project explored the concept of enough information, taking a naturalistic orientation and using qualitative techniques for data gathering and analysis. Both the study methodology and selected findings are discussed more fully elsewhere [3]. Study participants were public sector policy and research workers, in a variety of organisations ranging from small independent authorities and commissions to large bureaucracies. This group of public sector workers routinely prepare briefings, discussion and issues papers, carry out desk research and prepare written reports, all as input into the public policy decision making process [44].

The case summary in Figure 2 illustrates similarities in the experiences of the decision makers studied by NDM scholars and the experiences of Meg, one of the study participants. Meg worked as a policy officer in an organisation that advocates for children and young people. At the time of the study, Meg had four years experience in the public sector overall, two years of it with the organisation. Meg worked in a team of ten and much of her work involved preparing submissions to other government organisations. Generally this activity required both desk research and primary research with young people.

\section{Figure 2: Meg’s decision making}

Meg's task was to prepare a submission in response to another public sector department's decisions about young drivers. Among other responsibilities, this department regulated traffic rules for the state. The department had announced it was reviewing guidelines for young drivers and planned to bring in reforms aiming to improve safety for this group. Meg and her colleagues could see the proposed changes would be detrimental to the wellbeing of young people and decided to prepare a response. The dynamic, complex and ambiguous external environment in which Meg worked is captured in the definition of policy-making as "a point of relative firmness built into a continuing flow" [45: 15]. Policy work is characterised by "continuous work on persistent issues" [46: 189] with multiple stakeholders, such as interest groups, the media, public servants and advisory bodies, competing for attention [45, 47]. For Meg, uncertainty also came from working in a policy area in which she had little background or prior knowledge.

At the outset, there was confusion about exactly what Meg's organisation was supposed to be doing. Meg's team was unsure whether they should respond immediately to the department's announcement or wait to see if a discussion paper was released. The department then announced changes to the review process, indicating the process would commence with a consultation period. As part of this consultation process, the department released a discussion paper and Meg was given the task of preparing the organisation's formal response to the discussion paper. However until the department released the discussion paper, Meg was unable to start work on gathering information since she was unsure exactly what issues she would need to address in her response. This situation was a source of uncertainty and frustration. Further, because she knew little about road safety issues and her initial searches had found a substantial body of literature, Meg felt overwhelmed by the task she had been assigned.

Meg initially sought out the Young People's Reference Group, a standing group used by her organisation to provide guidance. She set up and facilitated focus groups with representatives of the age groups suggested by the 


\section{Jennifer M. Berryman}

Reference Group and, at the same time, commissioned the organisation's information manager to carry out database searches around topics and search terms she provided. Meg carried out her own desk research, sourcing and reviewing the references in the discussion paper released by the Department and using the web to source policy material from overseas and interstate jurisdictions. Meg was overwhelmed by the amount of information available, so for her, one challenge was making something useful out of it: "God, how do I make that into anything that could possibly be a real policy?" (IV 21, L552/3). Meg worked her way through the material and brought it under control by using as reference points the viewpoints of the young people interviewed. Once she had a clearer idea of what she was after, the gathering of the information was straightforward.

Although Meg was the only person working directly on the submission, she worked collaboratively, relying on advice from colleagues and supervisors, "grabbing anyone around" to use as a sounding board (IV 21, L 241). She relied on both colleagues and the Reference Group members to give her different points of view, which she found "just kind of help you to clarify in your mind" (IV 21, L 254) which issues needed priority and which were less significant.

The shifting and ill-defined goals towards which Meg worked were typified in a dilemma she had faced several times in the past. The literature and research findings would flag an issue as important or indicate that a solution worked. However, when Meg interviewed young people, she found they didn't see the topic as an issue or the solution as workable. Then she has to go back to "to fill in those gaps" (IV 21, L 301), talking again to the Young People's Reference Group, to the research participants or even commissioning a new group of participants. In this case, Meg found it especially difficult to deal with the dilemma. The young interviewees advised they did not want a certain proposal to be brought in by the Government. However, Meg knew from research findings that this response was effective in reducing death and injury in road accidents, and found herself thinking "God, which way do you go?” (IV 19, L 413). This dilemma necessitated “a trip back” (IV 21, L 322) to seek more input from young people, and in the end, she included both the research and the young people's views on the issue.

Meg did not really know if she had enough information until she started writing up the submission. This was a common experience for her, when a lack of flow in the written report can suggest that something is missing. At this stage, for a second time, Meg drew on her colleagues to give her feedback about whether or not she had missed something crucial.

Meg found the timeframes within which she had to work caused her stress. In the case of guidelines for young drivers, she found herself getting close to the deadline but still "going back and forth with changes a lot" (IV 21, L 401). Adding to the stress in this instance, a new issue surfaced in the media when Meg had almost finished the submission. It was an issue "we hadn't really talked about" (IV 21, L 403/4), so she had to go back and make sure she covered this new concern.

Not all the issues Meg dealt with at the organisation were matters of life and death. However she was aware that this submission, responding to proposed changes to guidelines for young drivers, had the potential to save lives. Meg felt "torn" (IV19, L407) when she looked at newspaper reports about "some young person who had died" (IV19, L409), knowing that had some recommended changes already been in place, for example, a curfew on young drivers, then that death might not have occurred.

Meg was relieved to get the submission written and off her desk and felt pleased that “... it's actually coming together. I never though it would" (V 21, L 360/1). But Meg also experienced stress at this stage, knowing that the submission would still have to "go through different people" (IV 21, L 395), people who would have different perspectives to hers, before its formal submission to the department.

In summary, the case description in Figure 2 illustrates an experience of judgements and decisions made during task-based information seeking that has a number of parallels with the decision making experiences of the experts studied by NDM researchers. It is suggested that NDM may be considered as a useful framework within which to consider judgements and decision making during information seeking. However, the NDM approach is not without critics. In the following section, the advantages and disadvantages of the approach are analysed. 
Jennifer M. Berryman

\section{NDM: A critical evaluation of what the approach offers LIS researchers}

There are two main benefits for LIS researchers offered by the NDM approach. The first benefit is that it provides a different conceptual framework within which to investigate how people make ongoing assessments, judgements and decisions throughout their information seeking, expanding the lens to allow us to see the process of human judgement and decision making as a holistic one. Secondly, it makes explicit the contextual factors that influence the decision making process.

Although decision theorists have recognised that decision making is "not a simple unitary event, but the product of a complex social process" [48: 35], research attention has continued to focus on the moment of choice. The NDM approach however provides a broader perspective which helps us see and understand how the process unfolds. As a research approach, NDM provides a framework within which to investigate that process holistically, and leading in turn to a richer understanding of judgement and decision making during information seeking. "Choosing among alternatives is one, but not the only, form of committing oneself [...] to a certain course of action" [49: 388]. The moment of choice may be less important than the judgements that precede that moment in developing an understanding of why particular courses of action are followed.

One of the most important lessons from NDM research findings is that the decision makers studied took the first acceptable option in the form of a feasible mental model. The experience then appears to have something in common with behavioural decision theory, with satisficing and the use of heuristics, and positions the use of mental models and ongoing assessment of the situation as a heuristic strategy [29], an understanding foreshadowed in 1982, when Kahnemann and Tversky [50] hypothesised a simulation heuristic. The process approach and taking the first feasible option emphasises the difficulty in evaluating the quality of the 'decision' that is made, in that there is often no one right decision or solution for the problem or task, and, indeed, no way to assess whether the decision or judgement was a good one [31]. There may be a number of different ways to reach an outcome.

Further, NDM research recognises the importance of contextual factors in shaping decision responses, with the explicit inclusion of the contextual factors at play. Illuminating these contextual factors may increase our understanding of why it is that people seem to not always follow the behaviour prescribed by the rational decision models, and how and why they deviate from them. As well, the holistic approach, the explicit recognition of situation awareness and the development of mental models provide a framework for understanding how individual information seekers constitute the context for their information seeking.

While the NDM approach has value for LIS researchers, it is not without drawbacks. One major group of criticisms of NDM is methodologically based: for example, the argument that NDM findings cannot be generalised, that the models are not normative, or the research not valid. In short, the work is not scientific [51]. These methodological concerns reflect a broader debate within the field of decision making, which remains firmly embedded in the positivist tradition and views more naturalistic and interpretive research as non-scientific [52]. This debate is part of a much broader discussion about the nature of scientific research and the issue, as it relates to NDM, is dealt with in detail by Lipshitz et al [49].

A second criticism targets perceived attempts of NDM researchers to differentiate their field from rational decision theory. One response to this is that rational decision research and NDM research are looking at different aspects of what is broadly referred to as decision making. The former is focused on the moment of choice where the evaluation of two or more alternative options is made, whereas the latter focuses more on the problem formulation and situation assessment stages [10]. This question of difference or complementarity also highlights the need to define clearly the phenomena being studied [10]. Indeed, one of the criticisms of NDM research has been the lack of clarity about the phenomenon being studied [53].

For LIS researchers, perhaps the most trenchant criticism of NDM is that as a body of research, it ignores the affective dimension of judgement and decision making. Most studies into human judgement and decision making have continued to focus on cognitive dimensions of behaviour [54]. NDM research continues in this vein, with its interest in the "cognitive processes of skilled decision makers" [53: 383] and its focus on mental models. Behavioural decision making theorists have recognised the power of affect in human judgement and decision making [15: 185] acknowledging that even "simple cognitive judgments [such] as recognition or identification of 


\section{Jennifer M. Berryman}

the features of a perceived object can be preceded by affective reactions” [13: 185]. Despite this recognition that the affective domain is important for understanding human judgement and decision making, decision theory continues to focus on cognitive aspects of decision making.

In summary, although the field is relatively new, it is argued that LIS researchers may find the NDM approach provides a useful conceptual framework within which to develop a richer understanding of how people make judgements and decisions while seeking and using information.

\section{Conclusion}

What can we learn from this brief overview of human judgement and decision making? Much decision making theory derives from research that focuses on the moment of choice. If a decision is understood as making a choice between alternatives, then at times, an information seeker may well be making decisions of this nature, for example, about information resources, on a sequential item by item basis. However, in this article, it is argued that studying this single point in a more complex process may constrain our understanding of how that choice or action has come about, since we have ignored what precedes it and often the context in which it happens.

It may be timely for LIS researchers to expand their 'theory repertoire' beyond a reliance on the theories of rational choice between two options. While useful for some research fields, for example, understanding consumer choice, these theories may be of less value as a model of all decision making during information seeking. If we truly aspire to understand the choices being made by information seekers, we must seek to understand the periods of "groping" or the "organised anarchy" [55: 90] that lead up to that moment of choice. NDM concentrates attention on judgement and decision making as a multi-stage and fluid process rather than as a choice between two or more options. The importance and the nature of the contextual factors which shape this process are also emphasised.

As we learn more about the nuanced assessments made continually throughout information seeking $[3,56$, 57], we need more nuanced ways to help us understand these assessments. As a different perspective on human judgement and decision making, NDM has much to offer LIS researchers as a conceptual framework within which to develop this richer understanding of decision making during information seeking.

\section{Acknowledgements}

The author wishes to thank the anonymous reviewers and the Editor for their valuable suggestions. Sincere thanks also to the study participants who so willingly shared their experiences.

\section{References}

[1] E. F. Harrison, The managerial decision-making process (5th ed) (Houghton Mifflin, Boston, MA, 1999).

[2] L. Zach, When is "enough" enough? modeling the information-seeking and stopping behaviour of senior arts administrators, Journal of the American Society for Information Science 56(1) (2005) 23-35.

[3] J. M. Berryman, What defines 'enough' information? How policy workers make judgements and decisions during information seeking: preliminary results from an exploratory study, Information Research 11(4) (2006) Paper 266. Available at http://InformationR.net/ir/11-4/paper266.html (accessed 13 March 2007).

[4] C. C. Kuhlthau, Seeking meaning: A process approach to library and information services (2nd ed) (Libraries Unlimited, Westport, CT, 2004). 
Jennifer M. Berryman

[5] D. Hardman and L. Macchi (eds), Thinking: psychological perspectives on reasoning, judgment and decision making (John Wiley, Chichester, 2003).

[6] D. E. Agosto, Sound, Colour and Action: Bounded Rationality and Satisficing in Young People's Examination of World Wide Web Resources (Unpublished doctoral dissertation, Rutgers, the State University of New Jersey, New Brunswick, 2001).

[7] H. Jungermann, The two camps on rationality. In: T. Connolly, H. R. Arkes and K. R. Hammond (eds), Judgment and decision making: An interdisciplinary reader, 2nd ed., (Cambridge University Press, Cambridge, England, 2000) 575-591.

[8] M. Browne, Organizational Decision Making and Information (Ablex, Norwood, NJ, 1993).

[9] R. M. Hogarth, Judgment and Choice (2nd ed) (John Wiley, Chichester, 1980).

[10] J. Kerstholt and P. Ayton, Should NDM change our understanding of decision making?, Journal of Behavioral Decision Making 14(5) (2001) 370-371.

[11] P. B. Kantor, A model for the stopping behaviour of users of online systems, Journal of the American Society for Information Science and Technology 38(3) (1987) 211-214.

[12] J. G. March, A primer on decision making: how decisions happen (Free Press, New York, NY, 1994).

[13] T. Tyszka, Information and evaluation processes in decision making. In: N. Eisenberg, J. Reykowski and E. Staub (eds), Social and Moral Values, (Lawrence Erlbaum Associates, Hillsdale, NJ, 1989) 175-93.

[14] C. W. Choo, The knowing organization: how organizations use information to construct meaning, create knowledge, and make decisions (Oxford University Press, New York, 1998).

[15] B. A. Mellers, A. Schwartz and A. D. J. Cooke, Judgment and decision making, Annual Review of Psychology 49(1) (1998) 447-477.

[16] B. R. Newell, Re-visions of rationality?, Trends in Cognitive Science 9(1) (2005) 11-15.

[17] H. A. Simon, Models of bounded rationality: Volume 3. Empirically grounded economic reason (MIT Press, Cambridge, MA, 1997).

[18] H. A. Simon, A behavioural model of rational choice, Quarterly Journal of Economics 69(1) (1955) 99-118.

[19] H. A. Simon, On the concept of organizational goal, Administrative Science Quarterly 9(1) (1964) 1-23.

[20] H. A. Simon, Models of Thought (Yale University Press, New Haven, 1979).

[21] G. Marchionini, Information seeking in electronic environments (Cambridge University Press, Cambridge, New York, 1995).

[22] D. H. Kraft and W. G. Waller, A Bayesian approach to user stopping rules for information retrieval systems, Information Processing and Management 17(6) (1981) 349-360.

[23] D. R. Morehead and W. B. Rouse, Models of human behavior in information seeking tasks, Information Processing \& Management 18(4) (1982) 193-205.

[24] A. Tversky and D. Kahneman, Judgment under uncertainty: heuristics and biases. In: T. Connolly, H. R. Arkes and K. R. Hammond (eds), Judgment and Decision Making: an Interdisciplinary Reader, 2nd ed., (Cambridge University Press, Cambridge, 2000) 35-52.

[25] P. M. Todd and G. Gigerenzer, Simple heuristics that make us smart (1999). Available at http://www.abc.mpib-berlin.mpg.de/users/ptodd/SimpleHeuristics.BBS/ (accessed 14 October 2003).

[26] D. E. Agosto, Bounded rationality and satisficing in young people's web-based decision making, Journal of the American Society for Information Science and Technology 53(1) (2001) 16-27.

[27] B. Perrin, M. B. J. Barnett, L. Walrath and J. D. Grossman, Information order and outcome framing: An assessment of judgement bias in a naturalistic decision making context, Human Factors 43(2) (2001) 227.

[36] P. Vakkari, Task-based information seeking, Annual Review of Information Science and Technology $37((2002)$ 413-485. 
Jennifer M. Berryman

[37] G. F. Smith, Managerial problem-solving: A problem-centred approach. In: C. E. Zsambok and G. Klein (eds), Naturalistic Decision Making, (Lawrence Erlbaum Associates, Mahwah, NJ, 1997) 371-380.

[38] R. Lipshitz and O. Ben Shaul, Schemata and metal models. In: C. E. Zsambok and G. Klein (eds), Naturalistic Decision Making, (Lawrence Erlbaum Associates, Mahwah, NJ, 1997) 293-303.

[39] T. Maqsood, A. D. Finegan and D. H. T. Walker, Biases and heuristics in judgment and decision making: The dark side of tacit knowledge. Proceedings of the Informing Science + Information Technology Education Joint Conference. Rockhampton, Qld. June 25-28 2004, 2004).

[40] L. R. Beach, Broadening the definition of decision making: The role of prechoice screening of options, Psychological Science 4(4) (1993) 215-220.

[41] R. Lipshitz, G. Klein, J. Orasanu and E. Salas, Focus article: taking stock of naturalistic decision making, Journal of Behavioral Decision Making 14(5) (2001) 331-352.

[42] P. Meso, M. D. Troutt and J. Rudnicka, A review of naturalistic decision making research with some implications for knowledge management, Journal of Knowledge Management 6(1) (2002) 63-73.

[43] M. R. Endsley, The role of situation awareness in naturalistic decision making. In: C. E. Zsambok and G. Klein (eds), Naturalistic Decision Making, (Lawrence Erlbaum Associates, Mahwah, NJ, 1997) 269-283.

[44] M. S. Feldman, Order without design: Information production and policy making (Stanford University Press, Stanford, CA, 1989).

[45] H. K. Colebatch, Policy (2nd ed) (Open University Press, Buckingham, 2002).

[46] M. Considine, Public policy: a critical approach (Macmillan, Melbourne, 1994).

[47] R. Gualtieri, Impact of the emerging information society on the policy development process and democratic quality. 1999, OECD Public Management Service. Public Management Committee: Paris. Available at http://www.olis.oecd.org/olis/1998doc.nsf/LinkTo/PUMA(98)15 (accessed 30 April 2007)

[48] H. A. Simon, Administrative decision making, Public Administration Review 25(1) (1965) 31-37.

[49] R. Lipshitz, G. Klein, J. Orasanu and E. Salas, Rejoinder: A welcome dialogue - and the need to continue, Journal of Behavioral Decision Making 14(5) (2001) 385-389.

[50] D. Kahneman, P. Slovic and A. Tversky, Judgment under uncertainty: heuristics and biases (Cambridge University Press, Cambridge, 1982).

[51] H. Jungermann, One mode of decision making (Research) - no less, no more, Journal of Behavioral Decision Making 14(5) (2001) 367-370.

[52] B. Flyvbjerg, Five misunderstandings about case study research, Qualitative Inquiry 12(2) (2006) 219-245.

[53] G. Whyte, Perspectives on naturalistic decision making from organizational behavior, Journal of Behavioral Decision Making 14(5) (2001) 383-384.

[54] G. Gigerenzer and D. G. Goldstein, Reasoning the fast and frugal way: Models of bounded rationality, Psychological Review 103(4) (1996) 650-669.

[55] H. Mintzberg and F. Westley, Decision making: It's not what you think, MIT Sloan Management Review 42(3) (2001) 89-93.

[56] T. Anderson, Relevance as process: Judgements in the context of scholarly research, Information Research 10(2) (2005) Paper 226. Available at http://informationr.net/ir/10-2/paper226.html (accessed 13 April 2007).

[57] N. Parker and J. M. Berryman, The role of affect in judging what is enough? In: D. Nahl and D. Bilal (eds), Information and Emotions: The Emergent Affective Paradigm in Information Behavior Research and Theory, (Information Today Inc, Medford, NJ, In press). 